\title{
HIDROSSEDIMENTOLOGIA, MEIO FÍSICO E COBERTURA DA TERRA NA UGRHI-22 PONTAL DO PARANAPANEMA-SP
}

\author{
Aline Aparecida dos Santos ${ }^{(a) ;}$ João Paulo de Oliveira Pimenta ${ }^{(\mathrm{b})}$ Paulo Cesar Rocha $^{(\mathrm{c})}$ \\ (a)Programa de Pós-Graduação em Geografia /FCT-UNESP/ aline.ap.as@ @otmail.com \\ (b)Programa de Pós-Graduação em Geografia /FCT-UNESP/ joaopaulo.pimenta@ hotmail.com \\ (c) Departamento de Geografia /FCT-UNESP/ pcrochag. @gmail.com
}

\section{EIXO: SISTEMAS GEOMORFOLÓGICOS: ESTRUTURA, DINÂMICAS E PROCESSOS}

\section{Resumo}

Este trabalho teve como objetivo realizar uma análise da concentração de sedimentos em suspensão e turbidez em 10 seções transversais de rios da UGRHI Pontal do Paranapanema, localizada no estado de São Paulo. Teve ainda como objetivo analisar as características do meio físico e cobertura da terra e a partir disso verificar o grau de interação entre as variáveis através de uma correlação matricial. A coleta de amostras de sedimentos em suspensão e a mensuração dos dados de turbidez foram feitas em campo. Em laboratório realizou-se a análise dos sedimentos através de filtragem. Foram usadas técnicas de geoprocessamento para a extrair informações do meio físico e um software de estatística para o tratamento dos dados. A análise da média de concentração de sedimentos demonstrou que houve variação significativa nos valores da carga entre as seções. Na análise de correlação a variável turbidez apresentou relação significante com as demais variáveis.

Palavras chave: bacia hidrográfica; hidrossendimentologia; turbidez; canal fluvial; correlação matricial.

\section{Introdução}

A bacia hidrográfica ou bacia de drenagem pode ser definida como uma área da superfície terrestre, drenada por um rio principal e seus afluentes (BIGARELLA \& SUGUIO, 1979). De acordo com Silva et al (2004) por esse conjunto de canais escoa água, sedimentos e materiais dissolvidos para uma saída comum.

De acordo com Christofoletti (1981), os sedimentos presentes em um canal fluvial são fornecidos pela sua remoção das vertentes e da ação erosiva da água nas margens e fundo do canal. Ainda segundo o autor, a origem e seu carregamento para os cursos d'águas recebe influência da quantidade e distribuição das precipitações, a estrutura geológica, as condições topográficas e a cobertura vegetal da bacia hidrográfica. Os sedimentos são constituídos por compostos orgânicos e inorgânicos, os quais provêm de fonte externa ou interna de um rio ou lago. Os compostos orgânicos compreendem microrganismos, restos de macrófitas e outros organismos de grande porte, em conjunto com os detritos provenientes de materiais em decomposição (GOLTERMAN et al., 1983). Os materiais inorgânicos, por sua vez, compreendem produtos resultantes de processos erosivos (fragmentos de rocha, siltes e argilas). 


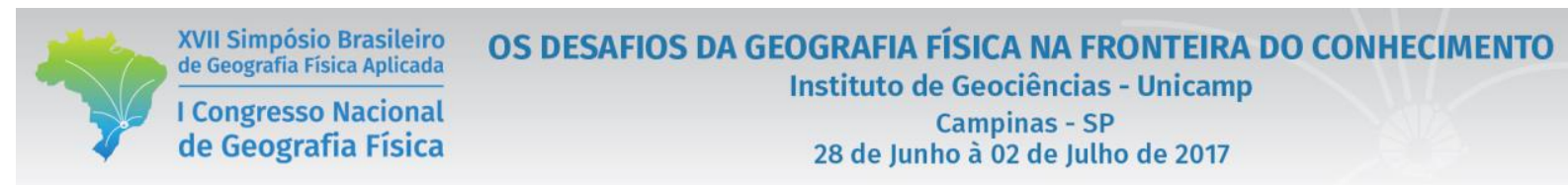

Compreende-se que a carga de sedimentos inorgânicos presentes no canal é formada por um conjunto de partículas com diferentes formas e tamanhos, que sofrem um processo de transporte variado conforme as condições locais e de escoamento. Referente a isso, Carvalho (2008, p. 74) aponta que "as forças que atuarão sobre a partícula podem mantê-la em suspensão ou no fundo do rio, saltando do leito para o escoamento, deslizando ou rolando ao longo do leito".

Os trabalhos hidrossedimentológicos são relevantes do ponto vista social, econômico e ambiental, uma vez que a produção e transporte de sedimentos interferem direta e indiretamente nas relações bióticas e abióticas de um sistema fluvial. Nesse sentido, este trabalho teve como objetivo realizar uma análise da concentração de sedimentos em suspensão e a turbidez em 10 seções transversais de cursos d'água pertencentes à Unidade Gerenciamento de Recursos Hídricos do Pontal do Paranapanema, e analisar as características do meio físico e cobertura da terra. A partir do levantamento dessas informações, foi possível realizar uma análise de correlação matricial e, assim, verificar o grau de interação entre as variáveis.

\section{1 Área de Estudo}

A área de estudo compreende parte da Bacia Hidrográfica do Rio Paranapanema, recorte pertencente à Unidade de Gerenciamento de Recursos Hídricos do Pontal do Paranapanema (UGRHI- 22). Localiza-se no oeste do estado de São Paulo (figura 1) e faz divisa com os estados do Mato Grosso do Sul e Paraná. Sua área de drenagem corresponde a $11.838 \mathrm{~km}^{2}$.

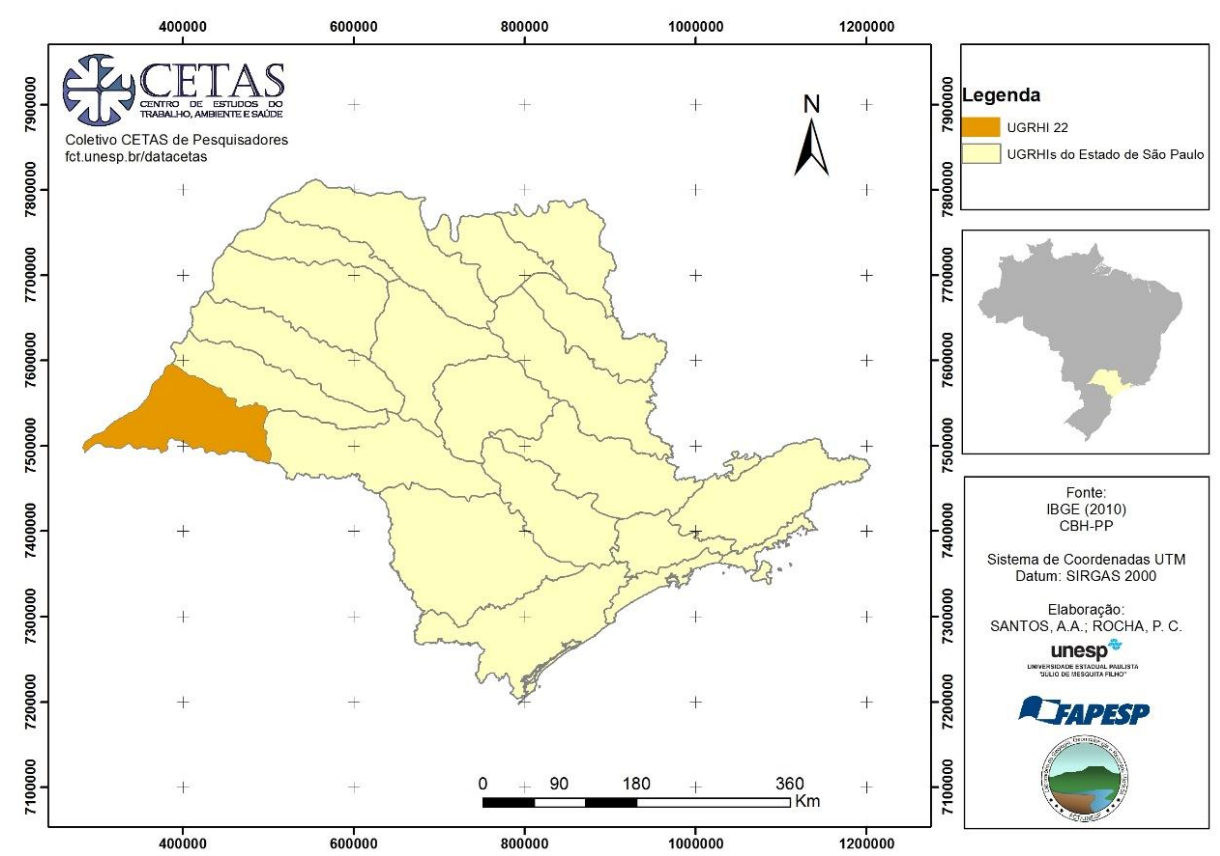

Figura 1 - Localização da Unidade de Gerenciamento de Recursos Hídricos 22 - Pontal do Paranapanema 
O clima do Oeste Paulista é do tipo tropical, situado em uma área de transição climática, compartilhada pelos sistemas atmosféricos inter e extratropicais (BOIN, 2000). A área é caracterizada pela presença de um período seco no inverno e um período chuvoso durante o verão.

O Oeste Paulista situa-se geomorfologicamente no Planalto Ocidental Paulista, que de acordo com Oliveira e Brannstrom (2004), foi moldado predominantemente em arenitos do Grupo Bauru e secundariamente em basaltos da Formação Serra Geral, subjacente aos arenitos. O relevo caracteriza-se como levemente ondulado com predomínio de colinas amplas e baixas com topos aplainados (ROSS \& MOROZ, 1997).

Boin (2000), cita que os solos da região do Oeste Paulista têm sua gênese de rochas areníticas do Grupo Bauru e de rochas básicas do Grupo São Bento (Serra Geral). Segundo Oliveira e Brannstrom (2004), solos com gênese no arenito são principalmente os latossolos vermelhos de textura arenosa e os argissolos vermelho-amarelos de textura arenosa média. Quanto aos solos derivados dos basaltos, são latossolos vermelhos de textura argilosa e nitossolos vermelhos.

A região do Pontal do Paranapanema, após ter suas matas derrubadas (início do século XX), teve sua produção agrícola voltada para culturas como algodão e café. Posteriormente, a partir da metade do século XX, a região se volta para a atividade de pecuária extensiva de corte e, após a década de 1950, começa a ser alvo da expansão do setor canavieiro com a instalação das primeiras unidades processadoras.

Esta região está localizada em uma porção do território brasileiro que, historicamente, traz uma intensa disputa pela posse da terra devido à invasão de grileiros que, com uso de violência e amparados por um contexto jurídico lento, foram se estabelecendo, tornando-se proprietários de extensas fazendas, muitas vezes improdutivas.

A atividade canavieira foi introduzida no Pontal do Paranapanema com os primeiros canaviais e plantas agroindustriais construídas e administradas pelos latifundiários da região, atraídos pelos incentivos fiscais e financeiros sendo, portanto, inseridos no circuito da produção do etanol (BARRETO, 2012). Além disso, a região do Pontal do Paranapanema apresenta-se com fortes atrativos que otimizam o processo de produção da cana-de açúcar, sendo responsáveis pela intensificação das disputas territoriais na região.

\section{Materiais e Procedimentos Metodológicos}

A coleta de amostras de água com material em suspensão foi realizada em 10 seções transversais localizadas em trechos de diferentes cursos d'água situados na UGRHI-22 (figura 2). A escolha das seções foi realizada com base nas características do meio físico (declividade e pedologia) e cobertura da terra das sub-bacias as quais os rios situam-se. 

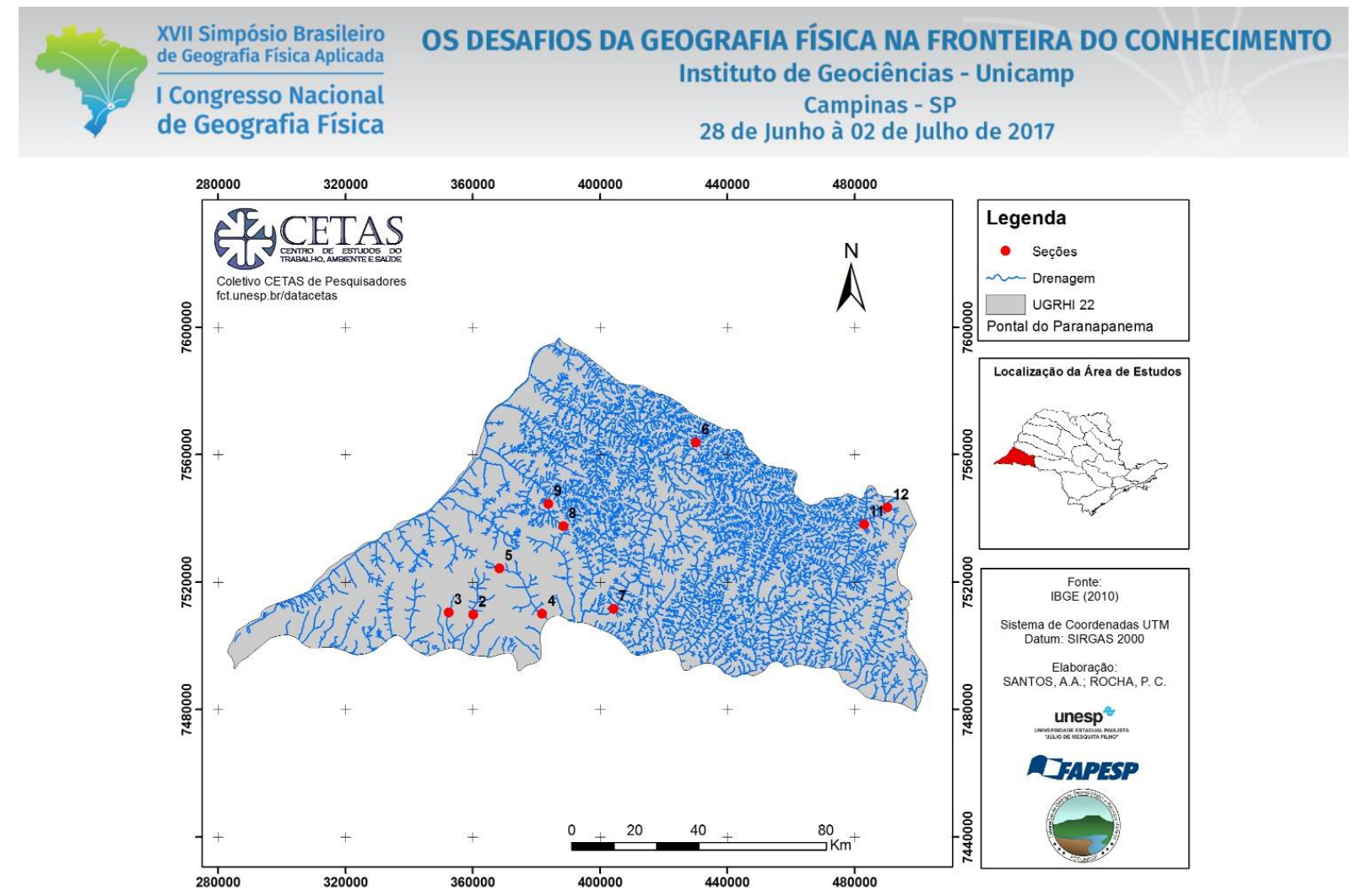

Figura 2 - Localização das seções de amostragem

As coletas em campo foram realizadas nos meses de fevereiro e maio de 2016, caracterizando períodos diferentes de acordo com o regime climático da região. Para análise espacial dos dados, utilizou-se a média dos valores obtidos entre os dois meses.

As amostras foram analisadas no Laboratório de Geologia, Geomorfologia e Recursos Hídricos da FCT/UNESP, baseada nos procedimentos utilizados por Rocha (2002). Para a análise, separou-se 200 $\mathrm{ml}$ de cada amostra e $200 \mathrm{ml}$ para a réplica, as quais foram filtradas em uma bomba a vácuo. Após esse processo, os filtros, anteriormente pesados, secaram na estufa durante uma hora, à temperatura de $105^{\circ} \mathrm{C}$. Posterior à secagem, as membranas filtrantes foram pesadas, para obter-se assim o peso do material suspenso a partir da subtração do peso inicial dos filtros pelo final.

O parâmetro turbidez foi mensurado em campo com o auxílio de um turbidímetro. Para o cálculo de vazão, foram medidas em campo a profundidade média do canal, a largura e a velocidade do fluxo. Os valores de vazão foram obtidos a partir da equação: Q (vazão) = P (profundidade média) x L (largura da seção) x V (velocidade média) (CUNHA, 1994).

Como aporte para discussão, foi realizado uma análise estatística de correlação entre a concentração de sedimentos em suspensão, vazão e turbidez com aspectos do meio físico da UGHRI 22, sendo estes a declividade e solos, além da cobertura da terra. As informações foram levantadas por meio de mapas temáticos e extraídas e tratadas a partir do Sistema de Informação Geográfica (SIG) ArcGis ${ }^{\odot} 10.1$.

O mapeamento pedológico utilizado neste trabalho corresponde ao realizado pela CPTI (Cooperativa de Serviços e Pesquisas Tecnológicas e Industriais) e o Comitê de Bacias Hidrográficas do Pontal do 


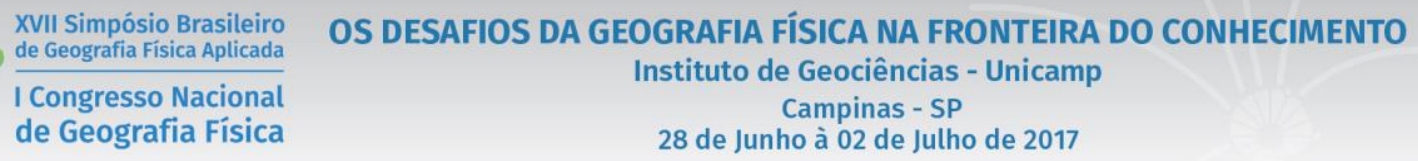

Paranapanema (CBH-PP) (1999). Os tipos de solos foram reclassificados de acordo com as classes de fragilidade de solos propostas por Ross (1994) para o mapeamento de fragilidade ambiental.

Utilizou-se o mapa de cobertura da terra de 2014 do Pontal do Paranapanema, confeccionado a partir de imagens de satélite do Landsat 8 pelo Grupo de Pesquisa Gestão Ambiental e Dinâmica Socioespacial (GADIS) da FCT/UNESP. Ambos os mapas fazem parte do banco de dados do CBH-PP.

No caso da cobertura da terra, os tipos de uso foram reclassificados baseado nos graus de proteção adotados por Ross (1994), na metodologia do mapa de fragilidade ambiental. A classificação é estabelecida a partir dos graus de proteção da cobertura vegetal em consideração a perda de solo. As classes são: muito alta, alta, média, baixa, muito baixa a nula.

O mapa de declividade foi produzido por meio de dados da missão Shuttle Radar Topography Mission (SRTM) no $\mathrm{ArcGis}^{\odot}$ e reclassificada com base nas classes sugeridas por Ross (1994). São elas: 0\% a 3\%; $3 \%$ a $6 \% ; 6 \%$ a $12 \% ; 12 \%$ a $20 \% ; 20 \%$ a $30 \% ;>30 \%$.

Para calcular a área $\left(\mathrm{km}^{2}\right)$ das variáveis do meio físico pertencentes as bacias de drenagem de cada seção amostrada, foi realizada a vetorização de polígonos a partir de curvas de nível geradas por imagens SRTM no $\operatorname{ArcGis}^{\mathcal{O}}$. Assim, foram criados arquivos vetoriais das áreas de drenagem de cada seção transversal, tornando possível extrair os dados de cada variável levada em consideração para a análise de correlação.

Os dados levantados foram organizados e tratados no software Excel $^{\odot}$. As análises estatísticas foram realizadas no software Statistica ${ }^{\circ}$.

\section{RESULTADOS E DISCUSSÃO}

\subsection{Hidrossendimentologia}

Em análise aos dados de sedimentos em suspensão, observou-se que no mês de fevereiro, a seção 3 apresenta maior carga de materiais suspensos em comparação as demais seções, conforme demonstra a tabela 1 .

Tabela 1 - Concentração de sedimentos em suspensão $(\mathrm{Mg} / \mathrm{L})$ por seção de amostragem.

\begin{tabular}{cccc}
\hline Seção/Período & Fevereiro 2016 & Maio 2016 & Média \\
\hline Seção 2 & 5,6 & 6,6 & 6 \\
Seção 3 & 40,0 & 10,5 & 25 \\
Seção 4 & 18,3 & 9,5 & 14 \\
Seção 5 & 14,3 & 27,3 & 21 \\
Seção 6 & 5,7 & 6,6 & 6 \\
Seção 7 & 12,0 & 23,0 & 17 \\
Seção 8 & 4,3 & 6,7 & 6 \\
Seção 9 & 6,5 & 22,5 & 14 \\
Seção 11 & 15,1 & 22,0 & 19 \\
Seção 12 & 7,4 & 12,8 & 10 \\
\hline
\end{tabular}

Fonte: dados obtidos em campo. 


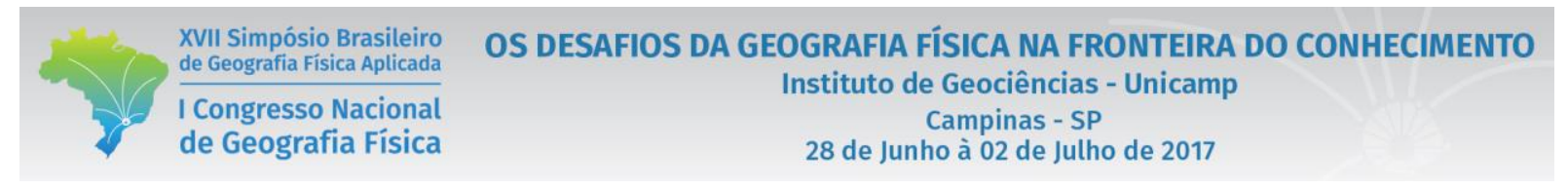

As seções 2, 6 e 8 apresentam as menores concentrações em fevereiro. No mês de maio a seção 5, 7, 9 e 11 possuem maior carga de sedimentos em comparação as outras, destacando as seções 2, 6 e 8 com os menores valores assim como no período anterior.

Em análise as médias, a seção 3 e 5 apresentam as maiores concentrações de sedimentos. Os menores valores foram verificados nas seções 2,6 e 8 .

Bigarella e Suguio (1979) e Christofoletti (1981), mencionam à relação entre a vazão do canal fluvial e a carga de sedimentos em suspensão. Estes autores apontam que o aumento da velocidade e da vazão cria condições energéticas para que a competência e a capacidade do rio sejam maiores. Neste sentido, a figura 3 apresenta a relação entre a média da concentração de sedimentos e a média da vazão nas seções:

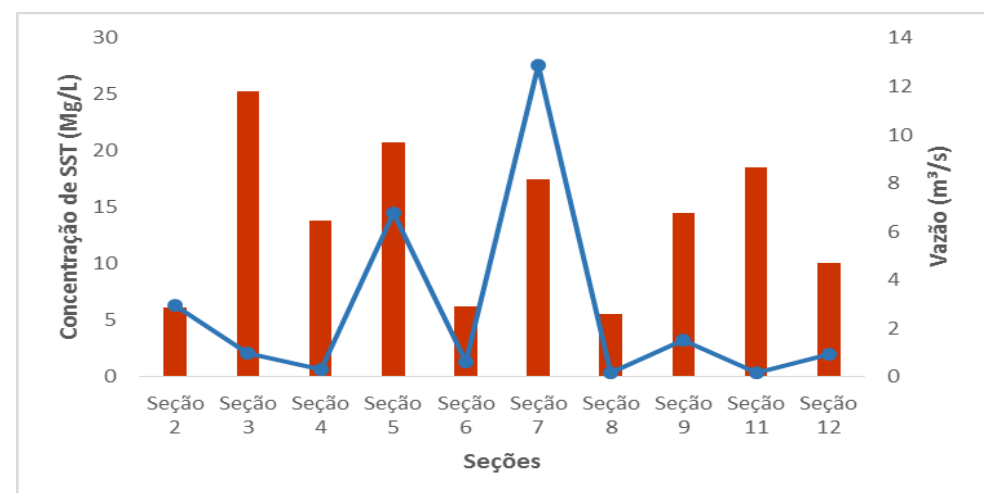

Figura 3 - Média da concentração de sedimentos em suspensão e da vazão nas seções.

De maneira geral, observou-se que as seções que apresentam valores de vazão mais elevados possuem menor carga de material em suspensão, exceto pelas seções 5, 6 e 7 .

A turbidez é um parâmetro de qualidade das águas que indica a presença de sólidos suspensos nos corpos d'água. A tabela 2 apresenta a turbidez média das seções.

Tabela 2 - Unidades Nefelométricas de Turbidez nas seções de amostragem.

\begin{tabular}{cccc}
\hline Seção & Turbidez (NTU) & Seção & Turbidez (NTU) \\
\hline S2 & 12 & S7 & 46,1 \\
S3 & 14,6 & S8 & 8,3 \\
S4 & 17,6 & S9 & 18,9 \\
S5 & 76 & S11 & 29,1 \\
S6 & 16,9 & S12 & 25,1 \\
\hline
\end{tabular}

Fonte: dados obtidos em campo. 


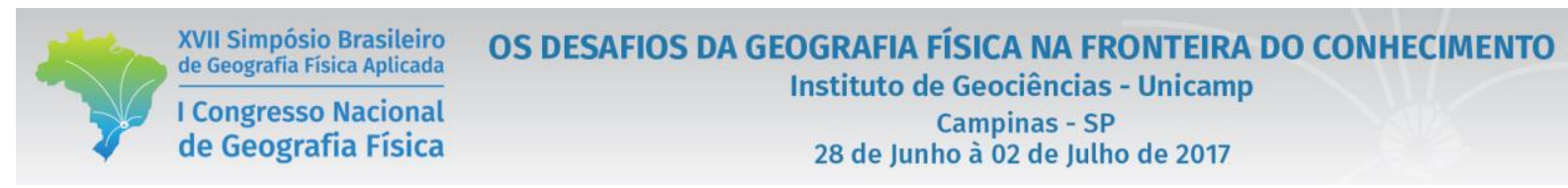

Notou-se que não houve significante variação entre os valores de turbidez nas seções, exceto pelas seções

5 e 7. A seção 5 apresentou um valor próximo ao padrão estabelecido pelo CONAMA $(<100$ NTU) para qualidade das águas.

\subsection{Meio Físico e Cobertura da terra}

Nas seções de amostragem, predominam unidades de relevo com declividades baixas a médias, conforme apresenta a tabela 3 .

Tabela 3 - Porcentagem das classes de declividade nas áreas de drenagem das seções

\begin{tabular}{ccccccc}
\hline \multirow{2}{*}{ Seções } & \multicolumn{7}{c}{ \% classes de declividade } \\
\cline { 2 - 7 } & $0 \%-3 \%$ & $3 \%-6 \%$ & $6 \%-12 \%$ & $12 \%-20 \%$ & $20 \%-30 \%$ & $>30 \%$ \\
\hline S2 & 30 & 56 & 14 & 0 & 0 & 0 \\
S3 & 29 & 55 & 15 & 0 & 0 & 0 \\
S4 & 24 & 54 & 21 & 1 & 0 & 0 \\
S5 & 13 & 31 & 44 & 10 & 1 & 0 \\
S6 & 11 & 37 & 48 & 4 & 0 & 0 \\
S7 & 28 & 40 & 29 & 2 & 0 & 0 \\
S8 & 12 & 43 & 43 & 2 & 0 & 0 \\
S9 & 15 & 43 & 39 & 3 & 0 & 0 \\
S11 & 20 & 50 & 30 & 1 & 0 & 0 \\
S12 & 31 & 56 & 14 & 0 & 0 & 0 \\
\hline
\end{tabular}

Fonte: Imagem de Radar SRTM (2000).

Segundo Ross (1994) as classes de declividade são usadas em estudos como indicativo de processos erosivos, risco de escorregamentos/deslizamentos e inundações. De acordo com a proposta deste autor (1994), o grau de fragilidade das classes de declividade das sub-bacias estudadas varia entre muito fraca, fraca e média.

Quanto aos solos, considerou-se as classes de fragilidade frente aos processos de escoamento superficial. A tabela 4 apresenta a classes de fragilidade dos solos das áreas estudadas:

Tabela 4 - Porcentagem de fragilidades dos solos nas áreas de drenagem das seções

\begin{tabular}{cccccc}
\hline \multirow{2}{*}{ Seções } & \multicolumn{5}{c}{ \% Fragilidade dos Solos } \\
\cline { 2 - 6 } & Muito Fraca & Fraca & Média & Forte & Muito Forte \\
\hline S2 & 0 & 71,6 & 0 & 28,0 & 0,3 \\
S3 & 0 & 85,5 & 0 & 14,5 & 0 \\
S4 & 0 & 39,3 & 0 & 60,7 & 0 \\
S5 & 0 & 10,4 & 0 & 89,6 & 0 \\
S6 & 0 & 0 & 0 & 100 & 0 \\
S7 & 0 & 40,2 & 0 & 58,9 & 1 \\
S8 & 0 & 24,1 & 0 & 75,9 & 0 \\
S9 & 0 & 29,0 & 0 & 71,0 & 0 \\
S11 & 0 & 5,5 & 0 & 94,5 & 0 \\
S12 & 0 & 100 & 0 & 0 & 0 \\
\hline
\end{tabular}

Fonte: CPTI; CBH-PP (1999) 


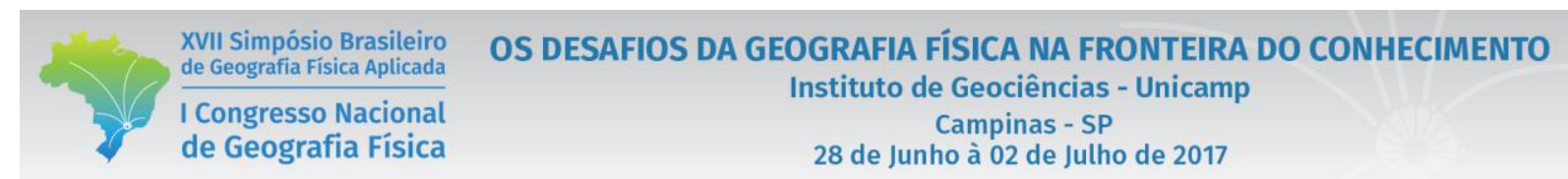

Em análise aos dados, verificou-se que predominam as classes fraca e forte nas áreas. Nas seções 2 e 3 há o predomínio de solos com fraca fragilidade, enquanto os solos das seções 4, 5, 7, 8, 9 e 11 caracterizamse por forte fragilidade. No caso da seção 12, o solo da área possui fraca fragilidade. A seção 6, por sua vez, apresenta solos com forte fragilidade.

A análise de proteção aos solos foi realizada de acordo com a cobertura da terra das áreas. A tabela 5 apresenta o grau de proteção encontrados em cada área.

Tabela 5 - Porcentagem dos graus de proteção da cobertura da terra nas áreas de drenagem das seções

\begin{tabular}{cccccc}
\hline \multirow{2}{*}{ Seções } & \multicolumn{5}{c}{ \% Graus de Proteção } \\
\cline { 2 - 6 } S2 & Muito Alto & Alto & Médio & Baixo & Muito baixo ou nulo \\
\cline { 2 - 6 } S3 & 67 & 0 & 0 & 33 & 0 \\
S4 & 2 & 0 & 0 & 98 & 0 \\
S5 & 5 & 0 & 0 & 95 & 0 \\
S6 & 2 & 0 & 0 & 98 & 0 \\
S7 & 0 & 0 & 0 & 100 & 0 \\
S8 & 4 & 0 & 0 & 96 & 0 \\
S9 & 0 & 0 & 2 & 98 & 0 \\
S11 & 0 & 0 & 0 & 100 & 0 \\
S12 & 4 & 0 & 0 & 96 & 0 \\
\hline
\end{tabular}

Fonte: GADIS; CBH-PP (2014)

Assim como demonstra a tabela, as áreas possuem cobertura com baixo grau de proteção, exceto pela seção 2. A área onde a seção está situada engloba a Unidade de Conservação do Parque Estadual Morro do Diabo, sendo coberta em sua maior parte por matas naturais.

\subsection{Correlação entre as variáveis do meio físico, cobertura da terra e hidrossedimentologia}

A partir de uma análise correlação múltipla é possível verificar o grau de interação entre diferentes variáveis. A tabela 6 apresenta a correlação entre as variáveis de sedimentos em suspensão (SS) e de turbidez com a variável vazão:

Tabela 6 - Correlação matricial entre as variáveis SS, turbidez e vazão

\begin{tabular}{cc}
\hline Variável & Vazão \\
\hline SS & $\mathbf{0 , 6 3}$ \\
Turbidez & $\mathbf{0 , 5 9}$ \\
\hline
\end{tabular}

Em análise aos dados, verificou-se que ambas as variáveis, SS e turbidez, apresentam correlação significante com a variável vazão. De acordo com Dias-Oliveira (2012), a vazão constitui-se em uma das propriedades que mais influência nos processos agradacionais/degradacionais sendo responsável pela construção e manutenção das propriedades geométricas contidas na seção transversal; entendendo-se por agradação e degradação processos de ajuste da descarga sólida. 


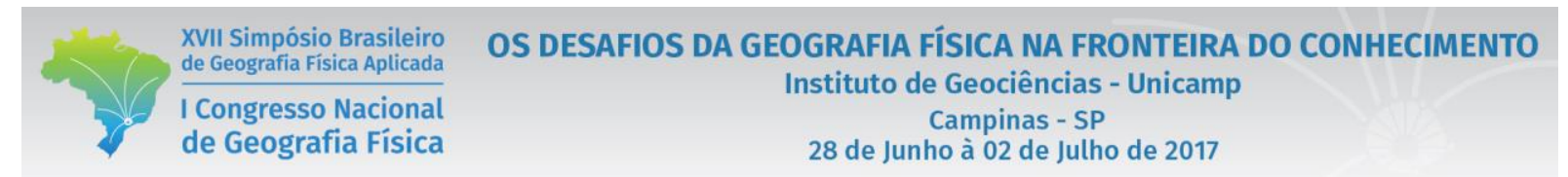

Com relação as classes de declividade, observou-se que apenas a turbidez apresentou grau significante de correlação, conforme a tabela 7:

Tabela 7 - Correlação matricial entre as variáveis SS, turbidez e classes de declividade

\begin{tabular}{ccccccc}
\hline \multirow{2}{*}{ Variável } & \multicolumn{6}{c}{ Declividade } \\
\cline { 2 - 7 } & $0 \%-3 \%$ & $3 \%-6 \%$ & $6 \%-12 \%$ & $12 \%-20 \%$ & $20 \%-30 \%$ & $>30 \%$ \\
\hline SS & 0,4 & 0,4 & 0,4 & 0,3 & 0,2 & 0,1 \\
Turbidez & $\mathbf{0 , 5}$ & $\mathbf{0 , 5}$ & $\mathbf{0 , 6}$ & $\mathbf{0 , 6}$ & $-0,4$ & $-0,6$ \\
\hline
\end{tabular}

Os valores destacados demonstram as correlações positivas significantes. Assim, verificou-se que a variável turbidez tem grau significativo de interação com unidades de relevo com declividades baixas a médias.

Referente aos solos, a variável SS apresentou grau significante de relação com a fragilidade forte. A tabela 8 apresenta os dados analisados:

Tabela 8 - Correlação matricial entre as variáveis SS, turbidez e fragilidade dos solos

\begin{tabular}{cccccc}
\hline \multirow{2}{*}{ Variável } & \multicolumn{5}{c}{ Fragilidade dos Solos } \\
\cline { 2 - 6 } & Muito Fraca & Fraca & Média & Forte & Muito Forte \\
\hline SS & $-0,3$ & - & $-0,2$ & $\mathbf{0 , 5}$ & $-0,2$ \\
Turbidez & - & $\mathbf{0 , 5}$ & - & $\mathbf{0 , 5}$ & $\mathbf{0 , 5}$ \\
\hline
\end{tabular}

A variável turbidez apresentou grau de interação significante com as classes de fragilidades fraca, forte e muito forte.

Quanto aos graus de proteção da cobertura da terra, apenas a variável turbidez apresentou correlação positiva significante, conforme demonstra a tabela 9:

Tabela 9- Correlação matricial entre as variáveis SS, turbidez e graus de proteção da cobertura da terra

\begin{tabular}{cccccc}
\hline \multirow{2}{*}{ Variável } & \multicolumn{5}{c}{ Graus de Proteção } \\
\cline { 2 - 6 } & Muito Alta & Alta & Média & Baixa & $\begin{array}{c}\text { Muito Baixa ou } \\
\text { Nula }\end{array}$ \\
\hline SS & - & 0,2 & - & 0,3 & 0,3 \\
Turbidez & 0,3 & - & 0,3 & $\mathbf{0 , 5}$ & $-0,6$ \\
\hline
\end{tabular}

A turbidez apresentou interação com os graus baixo e muito baixo de proteção. O grau de proteção da cobertura da terra, associado as condições de declividade e a fragilidade dos solos, pode indicar a ocorrência de processos erosivos na área. Parte do material carreado das vertentes chega aos canais fluviais, contribuindo na carga de materiais em suspensão (orgânicos e inorgânicos). 


\section{Considerações Finais}

A partir da análise da média de concentração de sedimentos em suspensão verificou-se que houve variação significativa nos valores das cargas entre as seções, destacando a variação de $19 \mathrm{mg} / 1$ entre a seção 3 e as seções 2, 6 e 8. Em uma perspectiva sazonal, a seção 3 apresentou um alto valor de concentração de sedimentos em fevereiro, período considerado chuvoso, se comparada as demais seções.

A seção 5 apresentou um alto valor de turbidez em comparação as outras seções, variando em 67,7 NTU em comparação a seção 8, a qual apresentou o menor valor de turbidez. Este nível de turbidez pode estar associado a forte fragilidade dos solos e ao baixo grau de proteção da cobertura da terra da sub-bacia a qual se situa.

De maneira geral, nas áreas de drenagem estudadas predominam solos com forte fragilidade e baixo grau de proteção da cobertura da terra. Quanto a declividade, predominam as classes de $0 \%$ a $12 \%$.

A variável turbidez apresentou relação significante com as variáveis do meio físico e a cobertura da terra, enquanto a variável de sedimentos em suspensão teve uma correlação significante apenas com uma classe de fragilidade do solo. Embora a turbidez seja um indicativo da quantidade de sedimentos suspensos no canal, esse parâmetro leva em consideração a carga total de sedimentos em suspensão, ou seja, materiais orgânicos e inorgânicos. Assim, a contribuição de material provindo da bacia hidrográfica presente no canal pode ter sido indicado mais expressivamente na variável de turbidez.

\section{Bibliografia}

BARRETO, M. J. Territorialização das agroindústrias canavieiras no Pontal do Paranapanema e os desdobramentos para o trabalho. Presidente Prudente: Universidade Estadual Paulista/Faculdade de Ciências e Tecnologia, (Dissertação de Mestrado em Geografia), 244f, 2012

BIGARELlA, J. J; SUGUIO, K. Ambiente fluvial. Curitiba, Editora Universidade Federal do Paraná e Associação de Defesa e Educação Ambiental, 1979. 172 p.

BOIN, M. N. Chuvas e erosões no Oeste Paulista: uma análise climatológica aplicada. 2000. 264 f. Tese (Doutorado em Geociências e Meio Ambiente) - Instituto de Geociências e Ciências Exatas, Universidade Estadual Paulista, Rio Claro.

BOTELHO, R. G. M.; SILVA, A. S. da. Bacia Hidrográfica e Qualidade Ambiental. In: VITTE, A. C.; Guerra, A. J. T. Reflexões Sobre a Geografia Física no Brasil. Rio de Janeiro: Bertrand Brasil, 2004. p. 153-192.

CARVAlHO, N. O. Hidrossedimentologia Prática. Rio de Janeiro: Interciência, 2008, 599p.

CHRISTOFOLETTI, A. Geomorfologia fluvial. São Paulo: Edgard Blucher, 1981. 296 p.

CUNHA, S. B. da. Geomorfologia fluvial. In: GUERRA, A. J. T.; CUNHA, B da. Geomorfologia: uma atualização de bases e conceitos. 4. ed., Rio de Janeiro: Bertrand Brasil, 1994. 211-252 p.

DIAS-OLIVEIRA, E. Geometria Hidráulica: algumas considerações teóricas e práticas. Sociedade e Território, v. 24, p. 166-184, 2012. 
DURLO, M. A; SUTILI, F. J. Bioengenharia: manejo biotécnico de cursos de água. Porto Alegre: EST edições, 2005. 189 p.

FLORENZANO, T. G. Introdução a Geomorfologia. In: FLORENZANO, T. G. Geomorfologia: conceitos e tecnologias atuais. São Paulo: Oficina de Textos, 2008, 12-25 p.

FLORENZANO, T. G. Cartografia. In: FLORENZANO, T. G. Geomorfologia: conceitos e tecnologias atuais. São Paulo: Oficina de Textos, 2008, 105-120 p.

FRANCISCO, F. C. de. Análise ambiental e consequências do desmatamento no município de Presidente Prudente no período de 1917 a 1986. Dissertação (Mestrado em Geografia) - Departamento de Geografia do Instituto de Geociências e Ciências Exatas da Universidade Estadual Paulista, Rio Claro, 1989.

GARDE, R. J. River Morphology. New Delhi: New Age International (P) Ltd, Publishers, 2006. 479 p.

GOLTERMAN, I. L; SLY, P. G; THOMAS, R. L. Study of the relationship between water quality and sediment transport. Paris: UNESCO, 1983. 231 p.

NOVO, E. M. L. de M. Ambientes Fluviais. In: FLORENZANO, T. G. Geomorfologia: conceitos e tecnologias atuais. São Paulo: Oficina de Textos, 2008, 219-246 p.

OLIVEIRA, A. M. S.; BRANNSTROM, C. Fundamentos da história ambiental do Planalto Ocidental do Estado de São Paulo. In: Anais Eletrônicos II Encontro Estadual de História ANPUH-BA. Feira de Santana, 2004.

ROCHA, P. C. Dinâmica Dos Canais No Sistema Rio-Planície Fluvial Do Alto Rio Paraná, Nas Proximidades De Porto Rico-PR. Tese (Doutorado em Ecologia de Ambientes Aquáticos Continentais) - Universidade Estadual de Maringá, UEM, Paraná, 2002.

ROSS, J. L. S. Análise empírica da fragilidade dos ambientes naturais e antropizados. Revista do Departamento de Geografia. V.8, 1994.

ROSS, J.L.S. \& MOROZ, I.C. Mapa Geomorfológico do Estado de São Paulo. São Paulo: Laboratório de Geomorfologia Depto de Geografia FFLCH-USP/Laboratório de Cartografia Geotécnica - Geologia Aplicada IPT/FAPESP, 1997. 63p.

SILVA, A. M.; SHULTZ, H. E.; CAMARGO, P. B. Erosão e Hidrossedimentologia em Bacias Hidrográficas. São Carlos: RiMa, 2004. 